\title{
KONSEP DAN APLIKASI HOMESCHOOLING DALAM PENDIDIKAN KELUARGA ISLAM
}

\author{
Tri Na'imah \\ Program Doktor Psikologi Pendidikan Islam Universitas Muhammadiyah Yogyakarta, Email : \\ trien.psikologi@gmail.com
}

\begin{abstract}
ABSTRAK
Penulisan artikel ini bertujuan untuk mengkaji model homeschooling, serta aplikasi homeschooling dalam pendidikan keluarga islam. Motif orangtua memasukkan anaknya ke homeschooling ada 2 kategori, yaitu motif ideologi dan motif paedagogi. Motif ideologi atau motif keagamaan orangtua yang kuat sehingga memasukkan anaknya ke homeschooling, sedangkan motif pedagogi adalah adanya anggapan bahwa lingkungan sekolah sering tidak memberikan pengalaman pendidikan yang baik. Berbasis pada motif ideologi, maka homeschooling dapat dipilih sebagai bentuk pendidikan keluarga islam. Homeschooling yang berbasis pendidikan fitrah berisi pendidikan tauhid, pendidikan ibadah, pendidikan akhlak, pendidikan kepemimpinan, dan pendidikan keahlian. Adapun metode yang dapat diterapkan metode hiwar, keteladanan, targhib \& tarhib dan Ibrah \&Mauizah.
\end{abstract}

Kata Kunci: Homeschooling; Pendidikan; Keluarga Islam.

\begin{abstract}
The writing of this article aims to examine the homeschooling model, as well as homeschooling applications in Islamic family education. There are two categories of parents putting their children into homeschooling, namely ideological motives and pedagogical motives. Strong ideological motives or religious motives that put their children into homeschooling, while pedagogical motives are the notion that the school environment often does not provide a good educational experience. Based on ideological motives, homeschooling can be chosen as a form of Islamic family education. Homeschooling based on fitrah education contains monotheism education, religious education, moral education, leadership education, and vocational education. The methods that can be applied are the methods of hiwar, exemplary, targhib \& tarhib and Ibrah \& Mauizah.
\end{abstract}

Keywords: Homeschooling; Education; Islamic Family. 


\section{PENDAHULUAN}

Lembaga pendidikan formal merupakan agen perubahan sosio kultural, sehingga lembaga pendidikan harus siap menjadi motor perubahan dalam menyikapi problem sosial dalam masyarakat. Namun, kenyataannya banyak fungsi dan peran lembaga pendidikan tidak berjalan sebagaimana semestinya. Misalnya, kritik terhadap pelaksanaan manajemen pendidikan yang masih birokratis. Sistem pendidikan saat ini kurang memberdayakan potensi anak, melainkan 'mengekang' dan semakin membuat anak tidak mampu menggali potensi dirinya. Pendidikan telah membunuh kreativitas peserta didik (Muniroh, 2009). Ujian Negara hanya menanyakan dimensi kognitif, sehingga menjadikan peserta didik tidak merasa perlu melakukan eksperimen di laboratorium, membaca novel, latihan mengarang, dan tidak perlu berdisiplin dalam berbagai kegiatan belajar yang hakikatnya diarahkan untuk menanamkan nilai dan mengembangkan sikap (Soedijarto, 2008). Akibatnya, sekolah formal cenderung mengejar nilai dan kurang mempromosikan keterampilan hidup dan keterampilan sosial (Mccabe, Treviño, \& Butterfield, 2001).

Kondisi ini semakin memotivasi orang tua memilih untuk mendidik anak-anak mereka di rumah, walaupun dengan risiko orangtua harus menyediakan banyak waktu dan energi (Patterson et al., 2007). Homeschooling menjadi tempat harapan orang tua untuk meningkatkan kualitasnya pendidikan anak-anak (Murray, Handyside, Straka, \& Arton-titus, 2013), mengembangkan nilai-nilai iman/agama dan moral serta mendapatkan lingkungan belajar yang menyenangkan (Lie, Andriyono \&Prasasti, 2014). Dengan demikian, motif orangtua memasukkan anaknya ke homeschooling dapat digolongkan menjadi ada 2 kategori, yaitu motif ideologi dan motif pedagogi (Van Galen, 1988). Beberapa orang tua memiliki motif keagamaan yang kuat sehingga memasukan anaknya ke homeschooling, sedangkan motif pedagogi adalah adanya anggapan bahwa lingkungan sekolah sering tidak memberikan pengalaman pendidikan yang baik, misalnya adanya bulying. Selanjutnya, motivasi sekunder orangtua muncul, berupa motif kuat dari orangtua untuk memenuhi kebutuhan anak berkebutuhan khusus, memperhatikan masalah medis anak-anak, dan menjaga masalah keselamatan dan keamanan anak (Hannah, 2011). Orang tua homeschooling percaya bahwa menjaga anak-anak mereka di rumah adalah cara terbaik untuk menghindari lingkungan sekolah yang mereka anggap terlalu keras. Keterlibatan langsung orangtua dalam pendidikan anak dianggap bisa menjamin kualitas pendidikan untuk anak-anak mereka (Green \& Hoover-Dempsey, 2007). Perkembangan homeschooling di Indonesia, di latar belakangi turunnya kepercayaan orangtua terhadap sekolah reguler. Kurikulum yang sering berganti menempatkan anak sebagai obyek pendidikan, sehingga menghambat oprimalisasi kesehatan mental 
anak (Simbolon, 2017).

Beberapa alasan orang tua memilih homeschooling sebagai pendidikan anaknya dapat dilihat dalam tabel berikut:

Tabel 1. Alasan Orang Tua Memilih Homeschooling

\begin{tabular}{lll}
\hline Alasan & 2003 & 2007 \\
\hline Kekhawatiran terhadap lingkungan sekolah & $85 \%$ & $88 \%$ \\
Keinginan untuk memberi pelajaran moral/agama & $72 \%$ & $83 \%$ \\
Tidak puas dengan pengajaran akademik di sekolah & $68 \%$ & $73 \%$ \\
Lebih suka pendekatan yang nonkonvensional & 0 & $65 \%$ \\
Memiliki anak berkebutuhan khusus & $29 \%$ & $21 \%$ \\
Anak memiliki masalah kesehatan fisik maupun mental & $16 \%$ & $11 \%$ \\
Alasan lain & $20 \%$ & $32 \%$ \\
\hline
\end{tabular}

Sumber: Bielick (2008)

Model pendidikan homeschooling ini meletakkan tanggung jawab secara penuh pada orang tua, karena model ini dianggap bisa memenuhi setiap kebutuhan anak. Orangtua terlibat langsung dalam pengembangan kurikulum, materi apa saja yang akan digali dan dikembangkan dari anak, memilih beragam metode pembelajaran yang tepat. Dalam hal ini tugas keluarga sangat penting, yakni menciptakan suasana pendidikan yang berkelanjutan (continues progress) guna melahirkan generasi penerus (keturunan) yang cerdas dan berakhlak (berbudi pekerti yang baik). Hal ini ditegaskan dalam UU No 20 Tahun 2003 tentang Sisdiknas pasal 7 ayat 2: “Orang tua dari anak usia wajib belajar berkewajiban memberikan pendidikan dasar kepada anaknya".

Hal itu juga sejalan dengan prinsip Islam sebagai agama yang sangat menekankan peran orangtua dalam mendidik anak, meskipun dahulu belum memakai istilah homeschooling. Sebagaimana yang telah digambarkan Allah swt. dalam kitab suci al-Qur'an, yang tertera pada Q.S. As-Syu'ara ayat 214:

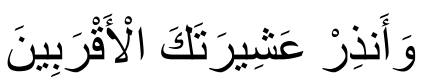

Artinya: "Dan berilah peringatan kepada kerabat-kerabatmu yang terdekat".

Ayat tersebut menjelaskan bahwa pertama kali yang diperintahkan Allah kepada nabi Muhammad saw dalam mengembangkan agama Islam adalah untuk mengajarkan agama itu kepada keluarganya, kemudian kepada masyarakat luas.

Ditekankan juga dalam QS At Tahrim ayat 6:

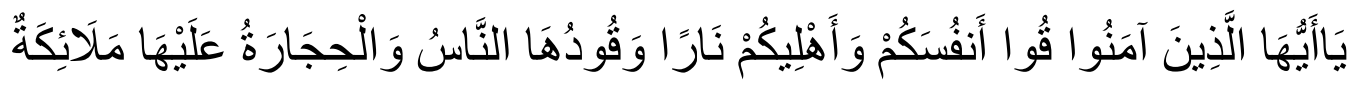




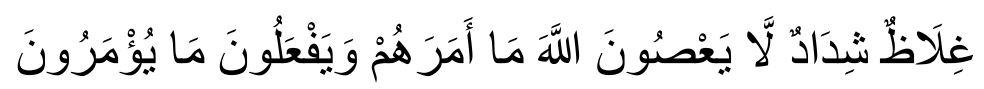

Artinya: "Hai orang-orang yang beriman, peliharalah dirimu dan keluargamu dari api neraka yang bahan bakarnya adalah manusia dan batu; penjaganya malaikat-malaikat yang kasar, keras, dan tidak mendurhakai Allah terhadap apa yang diperintahkan-Nya kepada mereka dan selalu mengerjakan apa yang diperintahkan".

Uraian tersebut menegaskan bahwa keluarga berfungsi menjadi pelindung dari perbuatan yang tercela, yaitu melalui pendidikan dalam keluarga khususnya dalam program homeschooling. Oleh karena itu perlu ada kajian yang mendalam tentang model homeschooling, kelemahan dan kelebihannya, serta aplikasi homeschooling dalam pendidikan keluarga Islam.

\section{PEMBAHASAN}

Secara umum homeschooling adalah model pendidikan yang menggunakan rumah sebagai basis pendidikan dan keluarga bertanggung jawab sendiri atas pendidikan anaknya (Sumardiono,2013). Kekhasan dan kekuatan homeschooling paling besar adalah customized education, artinya pendidikan yang disesuaikan dengan potensi anak dan lingkungan yang ada disekitar. Maka dalam homeschooling keragaman potensi anak dihargai dan anak tidak dituntut untuk sama dengan anak yang lain.

Homeschooling adalah sebuah aktivitas pendidikan untuk anak yang dilakukan di rumah, sehingga bisa menjadi pendidikan alternatif yang dipilih orangtua untuk mengembangkan nilai keagamaan, dan menciptakan suasana belajar yang lebih menyenangkan. Homeschooling akan membelajarkan anak-anak dengan berbagai situasi, kondisi, dan lingkungan sosial yang terus berkembang. Kedekatan orangtua dengan anak-anaknya dapat dijadikan metode belajar yang efektif dan merupakan pengalaman belajar yang sangat berharga bagi anak (Mulyadi, 2007).

Menurut Muhtadi (2008), karakteristik homeschooling adalah: 1) Berorientasi pada pembentukan karakter dan pengembangan bakat minat anak, 2) Kegiatan belajar lebih fleksibel sehingga merangsang anak untuk belajar mandiri, didampingi orang tua, tutor, atau masuk suatu komunitas. 3) Orang tua memegang peran utama sebagai guru, motivator, fasilitator, dinamisator, teman diskusi dalam proses belajar anak.4) Melibatkan guru atau tutor hanya sebagai pembimbing dan pengarah minat anak dalam mata pelajaran yang disukainya. 5) Jadwal belajar dan jumlah jam belajar fleksibel, 6) Pendekatan pembelajaran lebih bersifat personal dan humanis, yaitu memberi kesempatan anak belajar sesuai minat, kebutuhan, kecepatan dan kecerdasan masing-masing.

Berdasarkan uraian tersebut, tampaklah perbedaan antara homeschooling 
dengan sekolah formal yaitu dalam fleksibilitas penyelenggaraan kegiatan belajar, sehingga membuat anak lebih nyaman dalam belajar. Dalam pelaksanannya, Sumardiono (2007) mengatakan bahwa pendekatan yang digunakan dalam homeschoolingdapat dikategorisasikan dari yang sangat tidak terstruktur hingga yang sangat terstruktur, seperti belajar di sekolah. Beberapa model pembelajaran yang diterapkan dalam homeschooling antara lain:

1. School at-home, yaitu model homeschooling yang pelaksanaannya serupa dengan sekolah, tetapi bertempat di rumah. Model ini juga sering disebut textbook aproach, tradisional approach atau school approach.

2. Unit Studies yaitu model homeschooling yang berbasis pada tema. Dalam model ini, anak tidak belajar satu mata pelajaran tertentu (matematika, bahasa, IPA, IPS), tetapi mempelajari banyak mata pelajaran sekaligus melalui sebuah tema yang dipelajari. Model ini didasarkan asumsi bahwa proses belajar harusnya terintegrasi, tidak terpecah-pecah parsial.

3. The Living Books, yaitu model homeschooling melalui pengalaman dunia nyata. Implikasinya dengan mengajarkan kebiasaan baik, keterampilan dasar (membaca, menulis, matematika) serta memberi anak dengan pengalaman nyata, seperti berjalan-jalan, mengunjungi museum, berbelanja ke pasar, mencari informasi di perpustakaan, menghadiri pameran dan sebagainya.

4. Unschooling adalah pendekatan yang berangkat dari keyakinan bahwa anak-anak memiliki keinginan natural untuk belajar. Implikasi model ini dengan cara memfasilitasi kebutuhan anak berbasis minat, sehingga homeschooling tidak berbasis textbook.

Model-model tersebut merupakan alternatif yang dapat dipilih orangtua dalam menyelenggarakan homeschooling di rumah. Di Indonesia masih menjadi perdebatan apakah homeschooling perlu kurikulum atau tidak. Pada dasarnya pelaksanaan homeschooling tanpa kurikulum mungkin saja dilakukan. Namun demikian, keberadaan kurikulum akan lebih baik dan dapat membantu para orang tua yang baru menjalankan homeschooling serta mereka yang sibuk dan tidak memiliki banyak waktu di rumah.

Program homeschooling di Indonesia relatif baru, maka ada beberapa hambatan dalam pelaksanaannya. Hambatan dalam pelaksanaan homeschooling menurut Zahida \& Dewi (2016) antara lain sulitnya mencari legalitas lulusan. NISN (Nomor Induk Siswa Nasional) yang menjadi salah satu syarat administrasi bagi pelajar di Indonesia masih sulit kami dapatkan. Orang tua yang menjadi tutor di homeschooling seringkali kurang memiliki pengetahuan yang layak dan sering ketinggalan informasi berkaitan 
dengan aturan pemerintah yang berkaitan dengan pendidikan. Dalam UU No 20 tahun 2003 Pasal 27 Ayat (2), dinyatakan: "hasil pendidikan informal diakui sama dengan pendidikan formal dan nonformal setelah peserta didik lulus ujian sesuai dengan standar pendidikan nasional". Bunyi Pasal tersebut merupakan perlindungan peserta didik pada peluang untuk mengikuti Ujian Nasional Pendidikan. Hal ini menunjukkan bahwa pemerintah memberikan hak yang sama antara homescholer dengan siswa reguler untuk mengikuti ujian. Tetapi dalam pelaksanaannya banyak syarat administrasi yang menghambat keikutsertaan anak homeschooler dalam ujian.

Hasil penelitian Collom (2005) menunjukkan bahwa anak homeschooler tidak semuanya memiliki prestasi akademik baik, karena tidak semua orangtua sebagai tutor memiliki kemampuan akademik yang memadai. Ada beberapa orang tua homeschooler yang konservatif, yaitu cenderung mengajar anak-anak mereka di rumah dengan cara yang mereplikasi lingkungan kelas.

Romanowski (2001) menegaskan bahwa anak perlu terlibat dalam diskusi, berbagi ide-ide, dan bahkan bersaing dengan teman-teman mereka. Suasana belajar di kelas memberi kesempatan anak untuk berinteraksi dan berkomparasi di berbagai bidang dengan teman-temannya. Situasi seperti ini tidak ditemukan pada homeschooling, sehingga anak kurang mendapatkan pengalaman bersosialisasi akademik dengan teman-temannya. Wilhelm \& Firmin (2009) dan Beck (2001) juga mengakui bahwa masalah sosialisasi anak-anak menjadi problema yang paling signifikan untuk gerakan pendidikan di rumah. Mereka memiliki hubungan sosial yang terbatas lingkungan keluarganya, dan kondisi ini dikhawatirkan akan menghambat penyesuaian diri di dunia kerja nanti. Masalah sosial ini merupakan salah satu dampak dari perlindungan orangtua terhadap anak yang berlebihan. (Muniroh, 2009).

Dengan adanya beberapa kelemahan maupun hambatan dalam homeschooling, maka pelu ada regulasi/pengaturan yang jelas. Untuk mengetahui standar kemampuan anak, maka beberapa negara menerapkan tes prestasi berstadar nasional. Namun, walaupun ada hambatan dalam pelaksanaannya, homeschooling diakui memiliki keunggulan dibandingkan dengan sekolah reguler. Parker (2012) berpendapat bahwa homeschooling telah menanamkan tingkat kepercayaan diri yang tinggi pada anak, memiliki kepribadian yang berkembang dengan baik sehingga memungkinkan mereka untuk menjadi pembelajar yang sangat baik. Homeschooling membuat anak bebas untuk belajar apa saja yang mereka sukai dan mempelajari serta mencari tahu dengan media yang tersedia sehingga memacu rasa keingintahuan semakin tinggi. Anak- anak di homeschooling merasakan pengalaman yang berbeda dengan sekolah, antara lain dalam disiplin waktu, mandiri dan lebih memiliki planning (Ariefianto, 2017). 
Menurut Randa (2015) keunggulan homechooling adalah: 1) Pembelajaran dapat disesuaikan dengan kebutuhan anak dan kondisi keluarga, 2) Kegiatan pembelajarannya bisa lebih fokus, 3) Lebih memberikan peluang kemandirian dan kreativitas individual yang tidak didapatkan di sekolah, 4). Memaksimalkan potensi anak sejak usia dini, 5) Kesesuaian pertumbuhan nilai-nilai anak dengan keluarga relatif terlindung, 6) Biaya pendidikan disesuaikan dengan keadaan orang tua.

Dengan demikian, homeschooling lebih memberikan peluang untuk mencapai kompetensi individual semaksimal mungkin dan menjaga kualitas hubungan dengan keluarga. Ada tiga alasan utama orangtua memilih homeschooling untuk anaknya, yaitu untuk mendapatkan pelajaran moral dan agama yang lebih dibandingkan dengan sekolah reguler, kekhawatiran terhadap lingkungan sekolah dan ketidakpuasan terhadap pembelajaran akademik di sekolah reguler.

Hasil penelitian Sarwar (2013), menunjukkan keluarga muslim memilih homeschooling sebagai upaya menjaga fitrah anak, yaitu kondisi murni sebagai anak. Orangtua ingin melindungi dari perbuatan yang kurang baik, kekerasan, pacaran, bohong kepada orangtua. Homeschooling adalah lingkungan pendidikan alami yang berbeda dengan sekolah yang sengaja di setting untuk pendidikan.

Fitrah manusia adalah kejadian sejak semula atau bawaan sejak lahirnya (Shihab, 1998). Dari aspek bahasa fitrah dimaknai sebagai sifat bawaan alamiah manusia, sedangkan dari sisi agama fitrah merupakan keyakinan agama yang dibawa sejak lahir, yaitu fitrah bertauhid, atau mengesakan Tuhan (Baharuddin, 2007). Fitrah merupakan potensi dasar yang harus terus dipelihara dan dikembangkan sejak anak dilahirkan. Maka dari itu, peran orang tua menjadi begitu penting. Sebagaimana dalam QS Ar-rum ayat 30:

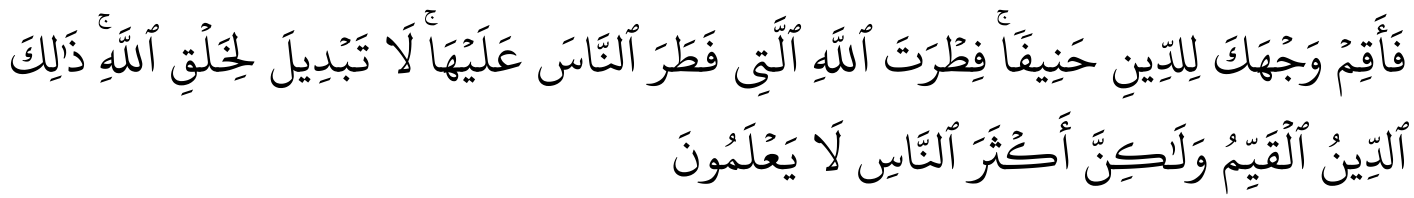

Artinya: "Maka hadapkanlah wajahmu dengan Lurus kepada agama Allah; (tetaplah atas) fitrah Allah yang telah menciptakan manusia menurut fitrah itu. tidak ada peubahan pada fitrah Allah. (Itulah) agama yang lurus; tetapi kebanyakan manusia tidak mengetahui”.

Manusia diciptakan Allah dengan membawa naluri beragama, yaitu agama tauhid. Jika ada manusia tidak beragama tauhid, maka hal itu terjadi karena besarnya pengaruh lingkungan dalam kehidupannya. Oleh karena itu tepat sekali alasan keluarga muslim yang memilih homeschooling sebagai upaya menjaga naluri tauhid anak. 
Berdasarkan hal tersebut, maka materi pendidikan anak untuk menjaga fitrah dikatakan oleh Murjaya \& Ali (2010) dikelompokkan dalam lima dimensi yaitu tauhid, ibadah, budi pekerti/moral/akhlak, dan keahlian. Homeschooling yang berbasis pendidikan fitrah dapat mengadopsi lima dimensi tersebut, yaitu:

1. Pendidikan tauhid adalah proses penanaman dalam hal menunggalkan Allah baik pada dimensi rububiyah, uluhiyah, dan kesumpurnaan nama dan sifat-Nya (Wahhab, 2004). Pendidikan tauhid merupakan penananman kesadaran dan keyakinan keesaan Alloh SWT beserta keagungannya ke dalam diri anak disertai dengan bimbingan agar anak memiliki jiwa tauhid yang kuat (Asmuni, 1993). Hal ini ditegaskan dalam QS Luqman ayat 13:

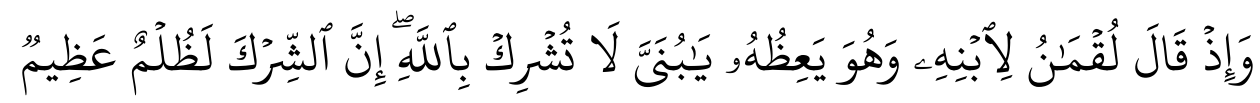

Artinya: "Dan (ingatlah) ketika Luqman berkata kepada anaknya, di waktu ia memberi pelajaran kepadanya: "Hai anakku, janganlah kamu mempersekutukan Allah, Sesungguhnya mempersekutukan (Allah) adalah benar-benar kezaliman yang besar".

Pendidikan keluarga merupakan pusat pendidikan tauhid yang pertama dan utama, maka orangtuapun dituntut untuk memiliki tauhid yang kuat agar bisa menjadi panutan anaknya. Untuk memberikan pendidikan tauhid dalam homeschooling perlu pendekatan afektif, berbasis pengalaman dan rasional.

2. Pendidikan Ibadah, yaitu implementasi dari pendidikan tauhid. Sebagaimana dalam QS Luqman ayat 17:

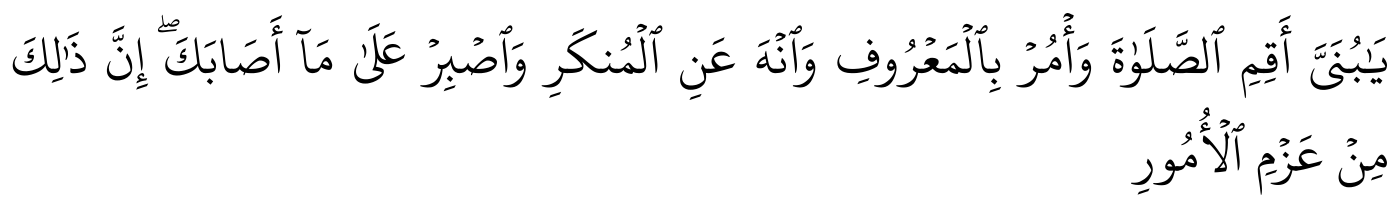

Artinya: "Hai anakku, dirikanlah shalat dan suruhlah (manusia) mengerjakan yang baik dan cegahlah (mereka) dari perbuatan yang mungkar dan bersabarlah terhadap apa yang menimpa kamu. Sesungguhnya yang demikian itu Termasuk hal-hal yang diwajibkan (oleh Allah)".

Ibadah merupakan tolak ukur ketauhidan manusia kepada Allah. Betapa pun ringannya perbuatan jika tidak dibiasakan akan terasa berat, sebaliknya jika perbuatan yang sangat beratpun kalau dibiasakan akan terasa ringan. Pendidikan ibadah bagi anak didik hendaknya dibiasakan dan dimulai sedini mungkin sebab tuntunan tersebut sesuai dengan ajaran Islam (Murjaya \& Aly, 2010).

3. Pendidikan budi pekerti, yaitu usaha sadar yang dilakukan dalam rangka menginternalisasikan nilai-nilai moral ke dalam sikap dan perilaku anak agar berakhlakul karimah dalam kehidupan sehari-hari, baik dalam berinteraksi dengan 
Tuhan, dengan sesama manusia maupun dengan alam/lingkungan (Heidar, 2004). Dalam konsep psikologi pendidikan Lickona (1992), mengatakan bahwa dalam proses pendidikan moral/budi pekerti, hendaknya guru/orangtua tidak semata-mata terfokus pada pemberian materi tentang konsep-konsep pendidikan moral/budi pekerti kepada anak, tetapi sampai terbentuknya karakter yang baik, yaitu pribadi yang memiliki pengetahuan moral, perasaan moral dan tindakan atau perilaku moral.

4. Pendidikan kepemimpinan, yaitu proses mendidik anak agar memiliki jiwa kepemimpinan antara lain mampu mempengaruhi orang, mengarahkan, memotivasi, kerjasama). Di dalam Islam konsep kepemimpinan sering disebut dengan khalifah yang berarti wakil, sebagaimana dalam QS Al Baqarah ayat 30:

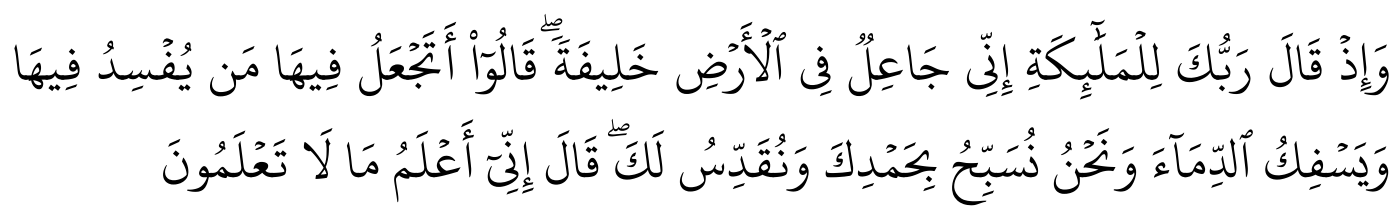

Artinya: "Ingatlah ketika Tuhanmu berfirman kepada Para Malaikat: "Sesungguhnya aku hendak menjadikan seorang khalifah di muka bumi." mereka berkata: "Mengapa Engkau hendak menjadikan (khalifah) di bumi itu orang yang akan membuat kerusakan padanya dan menumpahkan darah, Padahal Kami Senantiasa bertasbih dengan memuji Engkau dan mensucikan Engkau?" Tuhan berfirman: "Sesungguhnya aku mengetahui apa yang tidak kamu ketahui".

Selanjutnya digunakan pula istilah Ulil Amri yang satu akar dengan kata Amir sebagaimana disebutkan di atas. Kata Ulil Amri berarti pemimpin tertinggi dalam masyarakat Islam, seperti firman Allah swt dalam surat an Nisa' ayat 59.

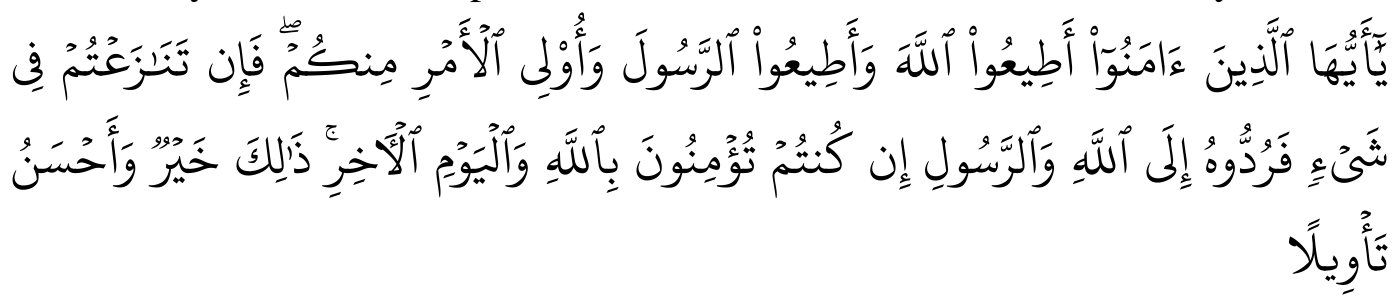

Artinya: "Hai orang-orang yang beriman, taatilah Allah dan taatilah Rasul (Nya), dan ulil amri di antara kamu. kemudian jika kamu berlainan Pendapat tentang sesuatu, Maka kembalikanlah ia kepada Allah (Al Quran) dan Rasul (sunnahnya), jika kamu benar-benar beriman kepada Allah dan hari kemudian. yang demikian itu lebih utama (bagimu) dan lebih baik akibatnya".

Berdasarkan ayat tersebut, maka pendidikan kepemimpinan harus diberikan sejak dini. Jiwa kepemimpinan bisa ditumbuhkan dengan pembelajaran di homeschooling karena memungkinkan anak mengalami langsung pengalaman kepemimpinan di lingkungannya. 


\section{Islãmadîna}

5. Pendidikan keahlian, yaitu pendidikan keterampilan yang diberikan kepada anak agar memiliki keahlian khusus sehingga mampu mengelola dan memanfaatkan alam semesta. Kreativitas dan kewirausahaan merupakan keterampilan esensial di abad ke-21. Kondisi lapangan kerja saat ini membutuhkan tenaga kerja yang kreatif dan inovatif. Oleh karena itu perlu ditumbuhkan jiwa kewirausahaan agar anak bisa survive hidup di masyarakat. Selain itu anak harus menguasai teknologi informasi, antara lain mampu mengakses, mengatur, mengintegrasi, mengevaluasi, dan menciptakan informasi melalui aplikasi teknologi komunikasi digital. Kemampuan ini memungkinkan anak menguasai keterampilan lain sehingga bisa mencapai kesuksesan dalam hidupnya (Trilling \& Fadel, 2009).

Berdasarkan uraian tersebut, maka homeschooling bisa memberikan pendidikan yang bersifat komprehenship. Adapun metode yang dapat digunakan orangtua antara lain:

a. Metode hiwar, yaitu bercakap-cakap antara orangtua dengan anak mengenai suatu topik. Percakapan itu dilakukan secara dinamis orangtua maupun anak terlibat langsung dalam pembicaraan sehingga menyebabkan proses belajar tidak membosankan.

b. Metode keteladanan (uswah hasanah), yaitu metode pembelajaran melalui perbuatan atau tingkah laku yang patut ditiru (modeling). Dalam Alqur'an Surat Al Ahzab ayat 21 disebutkan:

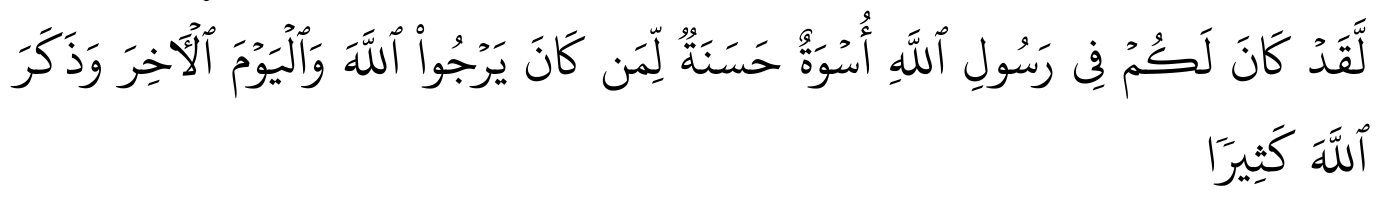

Artinya: "Sesungguhnya telah ada pada (diri) Rasulullah itu suri teladan yang baik bagimu (yaitu) bagi orang yang mengharap (rahmat) Allah dan (kedatangan) hari kiamat dan Dia banyak menyebut Allah".

Melalui suri tauladan yang baik anak dapat belajar akhlak yang mulia, sebaliknya jika suri tauladannya buruk anak akan terjerumus pada akhlak yang tercela. Menurut Bandura dalam social learning theory sebagian besar tingkah laku manusia dipelajari melalui peniruan (imitation) maupun penyajian contoh tingkah laku (modelling). Dalam hal ini orang tua memainkan peranan penting sebagai seorang model atau tokoh bagi anak untuk menirukan tingkah laku.

c. Metode targhib dan tarhib (pemberian reward dan punisment).

Manurut An - Nahlawi (1989), targhib adalah janji yang disertai dengan bujukan dan membuat ketertarikan terhadap suatu kebaikan, kenikmatan, atau kesenangan akhirat yang pasti dan baik, serta bebas dari segala bentuk keburukan, 
kemudian dengan melakukan amal saleh dan menjauhi rayuan dunia yang mengandung bahaya atau perbuatan jelek. Hal ini tidak lain dalam rangka menggapai keridhaan Allah swt yang merupakan rahmat Allah swt bagi hamba-hamba-Nya. Sedangkan tarhib adalah ancaman disertai dengan hukuman sebagai akibat dosa dan kesalahan yang dilakukannya dan merupakan perbuatan yang dilarang oleh Allah swt, serta perbuatan yang melalaikan perintah Allah swt. Tarhib dilakukan untuk menumbuhkan rasa takut anak, dengan memperlihatkan kebesaran dan keagungan-Nya agar selalu berhati-hati dalam bertindak.

Dalam konteks homeschooling, pengertian tersebut mengandung makna bahwa anak yang senantiasa tekun dan berbuat baik, maka sudah semestinya diberikan penghargaan oleh orangtua, sebaliknya anak yang melakukan perbuatan yang melanggar aturan agama mendapatkan hukuman yang sifatnya edukatif, agar anak menyadari kesalahannya dan tidak akan mengulang perbuatannya. Konsep reward dan punishment dalam teori behavioristik dimunculkan oleh Thorndike dengan istilah reinforcement atau penguat. Reinforcement merupakan penguatan dalam pembelajaran maka diperlukan untuk memberikan penguatan pada pembelajaran. Efek dari pemberian reinforcement terhadap penguatan perilaku jauh lebih besar dibandingkan dengan memberikan punisment untuk mengurangi munculnya perilaku negatif (Elliot, 2010).

d. Metode Ibrah dan Mauizah, yaitu cara menyampaikan materi dengan tutur kata yang berisi nasehat dan pengingat tentang baik buruknya sesuatu (Syahidin, 2009), dilakukan dengan menyentuh qolbu sehingga menggugah anak untuk mengamalkannya (An-Nahlawi, 1989).

Selain itu Sadid (2012), mengatakan sesuai dengan tujuan utama homeschooling yang berusaha melaksanakan pendidikan guna mengoptimalkan tumbuh kembang anak secara wajar, makapendekatan pembelajaran yang cocok adalah pembelajaran berorientasi pada paradigma konstruktivisme. Paradigma konstruktivisme merupakan pemberian keleluasaan anak dalam memanfaatkan semua potensi diri dan lingkungannya secara kreatif serta mandiri guna menciptakan dunianya sendiri.

\section{SIMPULAN}

Homeschooling merupakan bentuk pendidikan alternatif yang bisa dipilih orangtua. Motif orangtua memasukkan anaknya ke homeschooling ada dua kategori, yaitu motif ideologi dan motif paedagogi. Motif ideologi atau motif keagamaan orangtua yang kuat sehingga memasukkan anaknya ke homeschooling, sedangkan motif pedagogi adalah adanya anggapan bahwa lingkungan sekolah sering tidak memberikan pengalaman pendidikan yang baik. Dalam pelaksanaannya model 
homeschooling yaitu school at home, unit studies, the giving book, dan unschooling.

Berbasis pada motif ideologi, maka homeschooling dapat dipilih sebagai bentuk pendidikan keluarga islam. Homeschooling yang berbasis pendidikan fitrah berisi pendidikan tauhid, pendidikan ibadah, pendidikan akhlak, pendidikan kepemimpinan, dan pendidikan keahlian. Adapun metode yang dapat diterapkan metode hiwar, keteladanan, targhib \& tarhib dan Ibrah \& Mauizah.

\section{DAFTAR PUSTAKA}

An-Nahlawi. (1989), Prinsip dan Metode Pendidikan Islam, Bandung: Diponegoro

Ariefianto, L., (2017), Homeschooling: Persepsi, Latar Belakang dan Problematikanya (Studi Kasus pada Peserta Didik di Homeschooling Kabupaten Jember), Jurnal Edukasi, IV (2), 21-26

Asmuni, Y., (1993), Ilmu Tauhid, Jakarta: PT. Raja Grafindo

Baharuddin, (2007), Paradigma Psikologi Islami, Yogyakarta: Pustaka Pelajar

Beck CW. (2001). Alternative education and home schooling in Norway. Childhood Education, 77(6), 356-359.

Bielick, S., Chandler, K., and Broughman, S.P. (2001). Homeschooling in the United States: 1999 (NCES 2001-033). National Center for Education Statistics, U.S. Department of Education. Washington, D.C.

Collom E. (2005). The ins and outs of homeschooling: The determinants of parental motivations and student achievement. Education and Urban Society, 37(3), 307-335

Elliot, Stephen N., (2010), Educational Psychology: Effective Teaching, Effective Learning, McGraw-Hill

Green CL, Hoover-Dempsey KV. (2007). Why do parents homeschool? A systematic examination of parental involvement. Education and Urban Society, 39(2), 264-285

Heidar, P. D., (2004). Pendidikan Islam Dalam Sistem Pendidikan Nasional di Indonesia. Jakarta: Prenada Media

Hannah, L. G. (2012). Homeschooling education: Longitudinal study of methods, materials, and curricula. Education and Urban Society, 44(5), 609-631.

Lickona, T., (1992), Educating for Character, Hoe Our School can teach Respect \& Responsibility, New York: Bantam Book

Lie, A., Andriyono, T., \& Prasasti, S., (2014). Menjadi Sekolah Terbaik: praktik strategis dalam Pendidikan, Jakarta, Tanoto Foundation.

Mccabe, D. L., Treviño, L. K., \& Butterfield, K. D. (2001). Cheating in Academic Institutions : A Decade of Research. Ethics \& Behavior, 11(3), 219-232. 
Muhtadi, A., (2008), Pendidikan dan Pembelajaran di Sekolah Rumah (Home Schooling): Suatu Tinjauan Teoritis dan Praktis. http://staff.uny.ac.id/sites/default/files/132280878/11.\%20Pendidikan\%20dan\% 20pembelajaran\%20di\%20sekolah\%20rumah\%20(home\%20schooling

Mulyadi, S., (2007). Home Schooling Keluarga Kak Seto. Bandung: Kaifa

Muniroh, S. M. (2009). Homeschooling, Alternatif Pendidikan Humanistik (Studi Kasus Pembelajaran pada Pendidikan Alternatif Qaryah Thayyibah Kalibening, Salatiga, Jawa Tengah). Forum Tarbiyah, 7(1), 115-130.

Murjaya \& Aly, A., (2010), Materi Pendidikan Islam Berdasarkan Fitrah Manusia, Jurnal Penelitian Humaniora, 11 (1), 88-102.

Murray, M. M., Handyside, L. M., Straka, L. A., \& Arton-titus, T. V. (2013). Parent Empowerment: Connecting With Preservice Special Education Teachers. School Community Journal, 23(1), 145-168.

Parker EC. (2012). An intrinsic case study of two homeschooled undergraduates' decisions to become and remain Music education majors. Journal of Music Teacher Education, 21(2), 54-68

Patterson, J. A., Gibson, I., Koenigs, A., Maurer, M., Stockton, C., \& Taylor, M. J. (2007). Resisting Bureaucracy: A Case Study of Home Schooling. Journal of Thought, Fall-Winte, 71-86.

Randa, Valencia Mieke. (2015). Kelebihan dan Kekurangan Homeschooling. Tersedia di http://www.parenting.co.id

Romanowski, MH. (2001). Common arguments about the strengths and limitations of home schooling. The Clearing House: A Journal of Educational Strategies, Issues and Ideas, 75(2), 79-83

Sadid, A., (2012), Homeschooling: Pilihan Di Tengah Kegagalan Sekolah Formal, Jurnal Ilmiah VISI, P2TK PAUD NI, 7 (2), 159-172

Sarwar, S., (2013), What motivates 21st century Muslim parents to home-school their children? The College of Teachers practitioner Journal Education Today, 63 (4), 25-29

Shihab, M.Q., (1998), Wawasan Al-Qur'an, Bandung: Mizan

Simbolon, P., (2007). Homeschooling: Sebuah Pendidikan Alternatif, (Online), (http://pormadi.wordpress.com /2007/11/12/homeschooling/

Soedijarto. (2008). Landasan dan Arah Pendidikan Nasional Kita. Jakarta: Kompas.

Sumardiono, (2014), Apa Itu Homeschooling? Jakarta: Panda Median

Sumardiono. (2007). Homeschooling-A leap for better learning-Lompatan Cara Belajar, Jakarta: PT. Elex Media Komputindo Kelompok Gramedia

Syahidin, (2009), Menelusuri Metode Pendidikan dalam Al-Qur'an, Bandung: 


\section{Islãmadîna}

Alfabeta.

Trilling, B. and Fadel, C. 2009. 21st Century Skills: Learning for Life in Our Times. San Francisco, Calif., Jossey-Bass/John Wiley \& Sons, Inc

Van Galen, J. A. (1988). Ideology, Curriculuum, and Pedagogy in Home Education. Education and Urban Society, 21(1), 52-68. https://doi.org/10.1177/0013124588021001006

Wahhab, A., (2004). Kitab Tauhid Memurnikan La Ilaha llallah. Cet-10. Yogyakarta: Media Hidayah.

Wilhelm, GM, Firmin, MW. (2009). Historical and contemporary development in home school education. Journal of Research on Christian Education, 18(3), 303-315

Zahida, V,W. \& Dewi, W., (2016), Homeschooling Tunggal Sebagai Model Pendidikan Pilihan Bagi Anak (Studi Analisis Penerapan Konsep Homeschooling Pada Princess), Prosiding Seminar Nasional "Homeschooling Versus Sekolah Formal Dialog Tentang Mutu Pendidikan yang Bermartabat", 6 Oktober 2016, hal. 32-38. 